\title{
Digital Technologies and Traditional Cultural Expressions: A Positive Look at a Difficult Relationship
}

Mira Burri*

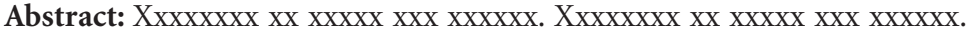

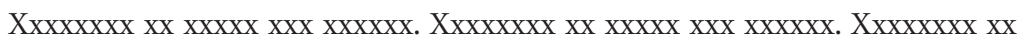

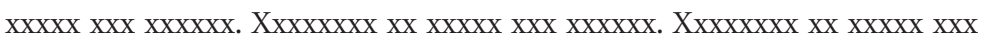

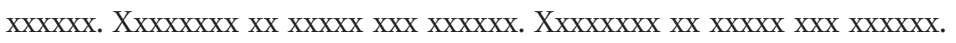

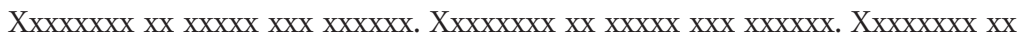

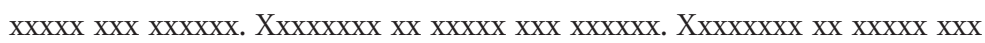

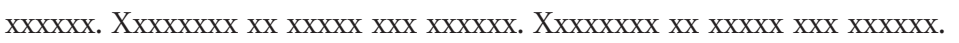
Xxxxxxxx $\mathrm{xx}$ xxxxx $\mathrm{xxx}$ xxxxxx.
\end{abstract}

Digital technologies have often been perceived as imperiling traditional cultural expressions (TCE). This angst has interlinked technical and sociocultural dimensions. On the technical side, it is related to the affordances of digital media that allow, among other things, instantaneous access to information without real location constraints, data transport at the speed of light, and effortless reproduction of the original without any loss of quality. ${ }^{1}$ In a sociocultural context, digital technologies have been regarded as the epitome of globalization forces-not only driving and deepening the process of globalization itself but also spreading its effects. A frequently made statement in this respect is that " $[t]$ he distinct and diverse qualities of the world's multiple cultural communities are threatened in the face of uniformity brought on by new technologies and the globalization of culture and commerce." 2

Yet, it is fair to say that digital technologies (or for that matter, any technologies) cannot be "bad" per se. It is the ways in which technologies are applied and

${ }^{*}$ World Trade Institute, University of Bern.

ACKNOWLEDGEMENTS: Thanks for constructive critique and insightful suggestions for improvement are owed to the two anonymous IJCP reviewers. 
the purposes they serve that may have (usually unevenly spread) positive or negative effects. ${ }^{3}$ It is also for the law to react to these effects in order to safeguard certain public interests and the attainment of goals important to society. ${ }^{4}$ It is one of the objectives of this article to show that in the context of the protection and promotion of TCE, rather counterintuitively, there are a number of ways in which digital technologies may act as benevolent factors. We illustrate in particular that some digital technologies can be instrumentalized to protect TCE forms, reflecting more appropriately the specificities of TCE as a complex process of creation of identity and culture. The article also seeks to reveal that digital technologies-and more specifically the Internet and the World Wide Web-have had a profound impact on the ways cultural content is created, disseminated, accessed and consumed. We shall argue that this environment may have also generated various opportunities for better accommodating TCE, especially in their dynamic sense of human creativity.

The article's argument unfolds in four main parts. Section 1 describes in more detail the salient features of digital technologies. Section 2 analyzes their impact on markets; consumer and business behavior; and, ultimately, the processes of formation, production, and expression of culture. Section 3 is intended to put these developments into the context of protection and promotion of TCE and explores the opportunities this newly created information and communication environment may have brought about. An essential element of this analysis is the legal framework, in particular those rules related to intellectual property protection, that may function as both a facilitator and an inhibitor to appropriately accommodating TCE and the indigenous communities as TCE producers within the global marketplace for cultural content. The final section provides a synthesis of our observations.

\section{DIGITAL TECHNOLOGIES: SOME SALIENT FEATURES}

At the core of the sweeping changes that we are about to describe is the process of digitization. Digitization allows for the expression of each and every type of content (be it audio, video or text) in a line of zeroes and ones and thereby creates a universal code for all information. As a consequence, it is irrelevant to the network whether the data being transferred is the video of the Apache sunrise ceremony, a picture of a sacred Aboriginal totem, or the latest hip-hop hit—-they will all be rendered into binary digits.

The ability of digital systems to handle an ever greater amount of multimedia content at lower and lower cost is a product of the exponential growth in the processing power and memory of microchips. ${ }^{5}$ As a third element of this technological matrix comes the perfection of optical fibers, which has led to enhanced breadth and capacity of networks ${ }^{6}$ and allowed the conveyance of digitized information at the highest speed possible. On top of this infrastructural layer came the 
Internet, as a global, publicly accessible network of interconnected networks, and the World Wide Web, which builds the logical layer of the Internet as a system of interlinked, hypertext documents. The latter ultimately allows us to reach the application and content layers, exploring web pages and creating, searching, and consuming a great variety of content. ${ }^{7}$

For the purposes of this article, both the affordances of digital technologies in a narrow technical sense (such as data conversion, transport, and access) and the impact of these technologies on the broader information and communication environment, on business and consumer behavior patterns, and on the processes of cultural creation and expression will be important. Bear in mind that all these processes, both taken as advances in technology and as societal changes, are never static but in constant and haphazard flux.

\section{DIGITAL TECHNOLOGIES AND THEIR IMPACT ON THE GLOBAL MARKETS FOR CULTURAL CONTENT}

\subsection{New Mechanisms, New Diversity}

By reducing information to zeroes and ones, digital representation radically modifies the characteristics of content. For one, it is freed from the need for a tangible medium, and it can be swiftly distributed at almost no cost. A second salient feature that has caused much uproar in both the big media conglomerates and small indigenous communities ${ }^{8}$ is the ability to make perfect copies. A third, less noted but perhaps the furthest reaching, characteristic of digital media is that they have changed the way information is organized and accessed. ${ }^{9}$

Under the broader category of digitally induced market modifications, ${ }^{10}$ as the reproduction, storage, and distribution of digital media products have a marginal cost close to zero, it becomes economically viable to sell relatively unpopular products. This creates incentives for suppliers to offer a larger and more diverse portfolio including "nonhit" titles that appeal to smaller niche audiences. This may be true for indigenous music, ${ }^{11}$ but it is also more generally applicable to offering products and services in a greater number of languages: Whereas most web sites are still in English, it is a fact that as the Internet becomes ubiquitous, people around the world prefer to read their news, stories, and local gossip in their own language. So, in parallel to the intensified globalization, one may also observe a process of localization. ${ }^{12}$ In this sense, for example, though most of the articles in the free online encyclopaedia Wikipedia are in English $(2,976,299)$, it contains content in 266 other languages, including Fiji Hindi, Igbo, and Māori. ${ }^{13}$

The digital setting may have also reduced the significant entrepreneurial risk inherent in launching new cultural goods and services ${ }^{14}$ (at least for some of them) while making their visibility greater. This is in stark contrast to the substantial 
storage and distribution costs in the offline world, where the shelf space (be it TV prime time or a Christmas cinema weekend) is limited. ${ }^{15}$

Traditional media companies have also faced (and still face) horrendous promotion costs, which were unbearable for smaller producers or individual artists. In the digital ecology, however, access to a wider audience is facilitated and made cheap. Supply and demand are also somewhat more easily "connected" as the Internet allows searching through a single point of entry. This search process is dynamic and in addition to the conventional search engines, other methods such as samples, feedback, and other advanced search tools based on collective intelligence ${ }^{16}$ enable users to discover even new products, eventually widening the diversity of content consumed. ${ }^{17}$

In the longer run, as consumers become more and more empowered to choose as we move from a "push" to a "pull" mode of content consumption (e.g., from classical broadcasting to on-demand), ${ }^{18}$ it is conceivable that consumer selection will constantly generate new and/or niche products. ${ }^{19}$ This would have the effect of inducing markets to offer new types of content, including, for example, archived or original works and director's cuts or performances, be they European, American, or African. ${ }^{20}$ This may ultimately lead to a greater share of available and effectively consumed "good" works, which, if realized, would be a genuine expression of cultural diversity. ${ }^{21}$

Another interesting implication relates to the fact that, in the digital environment, content remains accessible and usable long after its traditional one-off viewing at movie theatres, on TV, or through DVD rental or sale. ${ }^{22}$ Pulling content individually from a virtually unlimited selection of titles may in effect change the value attached to cultural content. Romantically put, this value would transcend the mere one-off use of content and offer incentives for creating good content, be it original, avant-garde, or traditional, which people would be willing to consume more than once.

To sum up these implications, digital technologies have fundamentally changed the conditions for participation in the communications environment as production and distribution costs fall and as the notion of scarcity is redefined.

\subsection{New Types of Content Production}

The second category of changes resulting from the properties and the dynamics of the digital space has to do with new modes of production of information, knowledge, and entertainment, whereby users become active creators, individually or as part of the community.

Due to the decreased costs of identifying like-minded groups of individuals and of communicating and acting together, ${ }^{23}$ the digital environment has given birth to multiple virtual communities and social networks. ${ }^{24}$ These allow for new type of community building and facilitate communication both within the said community and with external parties. In conjunction with these new forms of social 
interaction and much more critically for our present context, people online, equipped with diverse Web 2.0 tools, ${ }^{25}$ also create content. The idea that anyone with a computer and Internet connection (without the need of any intermedi$\left.\operatorname{ary}^{26}\right)$ can express her- or himself in a variety of ways and communicate with billions of people is very powerful, and this creative potential should be by all means accounted for.

Besides the intensified individual creation of content in the digital environment, a commons-based production of information has emerged, where "individuals band together, contributing small or large increments of their time and effort to produce things they care about." ${ }^{27}$ These changes not only relate to what some call "amateurs" 28 but also profoundly affect how all artists and culture makers express themselves, how they communicate with one another and with the public, how cultural content is presented and made accessible, and how it is consumed. ${ }^{29}$

\section{IMPLICATIONS FOR THE PROTECTION AND PROMOTION OF TRADITIONAL CULTURAL EXPRESSIONS: SKETCHING SOME OPPORTUNITIES}

Before we consider the possible effects of the above processes on the modes of TCE protection and promotion, a definition of the notion of TCE is due. Although a number of definitions of TCE exist in national and regional laws and in international instruments, ${ }^{30}$ there is presently no internationally settled common definition. The World Intellectual Property Organization's (WIPO's) Draft Provisions on $T C E^{31}$ do however offer a broad description of what constitutes TCE (but expressly leave the choice of terms denoting the protected subject matter to national and regional fora). ${ }^{32}$ Pursuant to this description, "'traditional cultural expressions' or 'expressions of folklore' are any forms, whether tangible and intangible, in which traditional culture and knowledge are expressed, appear or are manifested." These may comprise or be combinations of "(i) verbal expressions, such as ?2? stories, epics, legends, poetry, riddles and other narratives; words, signs, names, and symbols; (ii) musical expressions, such as songs and instrumental music; (iii) expressions by action, such as dances, plays, ceremonies, rituals and other performances, whether or not reduced to a material form; and (iv) tangible expressions, such as productions of art, in particular, drawings, designs, paintings (including body-painting), carvings, sculptures, pottery, terracotta, mosaic, woodwork, metalware, jewelry, baskets, needlework, textiles, glassware, carpets, costumes; handicrafts; musical instruments; and architectural forms." ${ }^{33}$

This "draft description," as the WIPO calls it, ${ }^{34}$ already gives a sense of the staggeringly wide range of expressions that qualify as TCE, comprising both "preexisting materials dating from the distant past that were once developed by 'authors unknown' through to the most recent and contemporary expressions of tradi- 
tional cultures, with an infinite number of incremental and evolutionary adaptations, imitations, revitalizations, revivals and recreations in between." 35 The essential qualification that sets these expressions apart from any other cultural expression is the "defining characteristic of 'traditional", 36 whereby all creations "identify a living tradition and a community that still bears and practices it." ${ }^{37}$

Despite the preceding guidelines on identifying TCE, it should be noted that the term "TCE" may often be an ill-suited, somewhat artificially constructed shortcut to depicting an extremely complex reality whose limits are indefinable and whose elements may be in themselves complex notions, such as the concept of "dreaming" of Australia's indigenous peoples. ${ }^{38}$ TCE are also not a static but a highly dynamic, living system, which is constantly in the process of renegotiation, innovation, and creation. ${ }^{39}$ Furthermore, and accounting for the indigenous communities' perspective, it is to be acknowledged that they commonly "regard all products of the human mind and heart as interrelated, and as flowing from the same source: the relationships between the people and their land, their kinship with the other living creatures that share the land, and with the spirit world." ${ }^{40}$

The indigenous peoples' demands for protecting and promoting TCE are accordingly heterogeneous. ${ }^{41}$ In a narrow context, which is also the most policy relevant, indigenous communities strive for intellectual property (IP) protection. They wish to distinguish this "IP protection" "from the 'safeguarding,' 'preservation' and 'promotion' of cultural heritage, which refer generally to the identification, documentation, transmission and revitalization of tangible and intangible cultural heritage in order to ensure its maintenance or viability." 42 At the same time, indigenous peoples do acknowledge that many of their aspirations relating to TCE may be addressed by non-IP measures targeted at preservation and promotion of cultural heritage as well as by other tools, such as those developed under communities' customary laws. ${ }^{43}$

In this sense, when talking about "TCE protection," and although we repeatedly stress the dynamic character of TCE, it seems that "current disputes center on items of TK [traditional knowledge] as they now exist." ${ }^{44}$ The concrete goals pursued through the IP protection may, however, differ. On the one hand, some communities wish to claim and exercise IP in their TCE to enable them to exploit them commercially as a contribution to economic development. On the other hand, some communities wish to exercise IP rights in order to prevent the use and commercialization of their TCE by others (including culturally offensive or demeaning use, and use that inaccurately represents their cultures). Finally, many communities are concerned with preventing others from gaining or maintaining IP over their TCE. This would entail defensive mechanisms to block third parties' IP rights if these are considered prejudicial to the community's interests or IP rights obtained without the consent of the community (the so-called "defensive protection"). ${ }^{45}$

In the following analysis, we look at both the opportunities for TCE protection and for TCE promotion and do not follow the strict lines of IP protection as understood in the work of the WIPO's Intergovernmental Committee on Intellectual 
Property and Genetic Resources, Traditional Knowledge and Folklore (IGC). ${ }^{46}$ Rather, we adopt a broader approach along the lines of the UNESCO Convention on the Protection and Promotion of the Diversity of Cultural Expressions. ${ }^{47}$ In the next two sections, we map out some tools that the digital environment has provided for the protection and promotion of TCE. ${ }^{48}$ In this inquiry, we do not discuss in detail the adoption of digital technologies by different indigenous communities. While we do not undervalue the fact that many of them tend to be materially poor ${ }^{49}$ and that the digital divide is a reality, anecdotal and empirical evidence shows that indigenous peoples have been active users of the Internet for quite some time. ${ }^{50}$ Some even argue that "the Internet is an ideal match for $\mathrm{Ab}$ original tribes, providing the necessary economy of scale to support electronic publishing for such small constituencies ... because the Internet can support an admixture of audio, video, and text, transcending the print medium, it is ideally suited to the oral story-telling traditions of the Aboriginal Community." 51

Although some communities still reject the Internet as a medium, the contact of indigenous communities with digital technologies has clearly been intensified in recent years, both as the network expands and as communities themselves become more willing to enter the digital space. This process has been facilitated by a growing number of more suitable applications that reduce the media literacy threshold and apply step-by-step learning tools. Beyond these efforts, digitized indigenous content enters the globalized digital space through various other channels, such as museum and archiving activities, nongovernmental organization (NGO) initiatives, and diverse research and language preservation projects. ${ }^{52}$

\subsection{Tools to Protect}

The modern IP system provides for a broad palette of sophisticated ${ }^{53}$ and flexible tools that allow us "to protect both traditional and new forms of symbolic value produced in particular places as they circulate in global commodity markets." 54 At the same time, the IP system is far from perfect and shows substantial deficiencies with particular regard to TCE. Most of the limitations are inherent in the nature and the mechanisms of protection and relate to the centrality of authorship, originality, and mercantilism to the "Western" IP model. As a result, numerous non-Western, collaborative, or folkloric modes of production are left outside the scope of IP protection, ${ }^{55}$ and there is a sort of a dissonance between the contemporary IP rights and TCE as the subject matter of protection. The rise and spread of global media have only exacerbated this discord, while at the same time significantly raising the economic stakes in protecting traditional knowledge for both the indigenous communities and for its nonindigenous, allegedly unlawful, users. ${ }^{56}$

With specific regard to copyright, which is the most relevant protection mechanism $^{57}$ as far as TCE are concerned, ${ }^{58}$ the following limitations have been identified as especially worrisome: 
1. Originality. Copyright protects only original works, and many traditional literary and artistic productions are not original in this sense. Similarly, traditional designs are not deemed new or original for industrial designs protection. At the same time, adaptations of TCE can be protected as original copyright works and designs, leading to calls for defensive protection.

2. Ownership. Protection of copyright and industrial designs requires the identification of a known individual creator or creators in order to determine the holders of rights and identify precisely who might benefit from such rights. It is difficult, if not impossible, however, to identify the creators of TCE and hence the right-holders and beneficiaries in TCE, because TCE are communally created and held, or because the creators are unknown or unlocatable. The very concept of ownership in the IP sense may also be alien to many indigenous peoples.

3. Fixation. The fixation requirement existing in many national copyright laws prevents intangible and oral expressions of culture, such as tales, dances, or songs, from being protected unless and until they are fixed in some form or media. Even certain fixed expressions, such as face painting, body painting, and sand carvings, may not meet the requirement. Yet, rights in recordings and documentation of TCE vest in the people responsible for these acts of fixation, such as ethnomusicologists, folklorists, and other researchers, and not in the TCE bearers.

4. Term of protection. The limited term of protection in copyright, related rights, and industrial designs is claimed to be inappropriate for TCE. It fails to meet the need to protect TCE in perpetuity or at least as long as the community exists. The limited term of protection also requires certainty as to the date of a work's creation or first publication, which is often unknown in the case of TCE.

5. Exceptions and limitations. Apart from the limited term of protection for most IP forms, it has been argued that other exceptions and limitations commonly found in IP laws are not suitable for TCE. For example, typical copyright exceptions that allow a sculpture or work of artistic craftsmanship permanently displayed in a public place to be reproduced in photographs or drawings without permission may seriously disturb indigenous sensibilities and undermine customary rights.

6. Defensive protection. Indigenous peoples and communities are concerned about nonindigenous companies and persons imitating or copying their TCE or using them as a source of inspiration, and then acquiring IP protection over their derivative work, design, mark, or other production. Communities have expressed, for example, concerns over the use by external parties of words, names, designs, symbols, and other distinctive signs in the course of trade or over their registration as trademarks. ${ }^{59}$ Furthermore, neither copyright nor industrial design laws protect the style of literary and artistic works and designs. ${ }^{60}$ 
To remedy these deficiencies, a number of efforts are being made under the auspices of WIPO and others that seek to provide legal protection for TCE and for traditional knowledge (TK) "as an essential corrective for the international community as well as individual nations to undertake." ${ }^{\prime 1}$ Most of these initiatives take as self-evident the proposition that TCE and TK ought to be protected, and they explore ways of doing so by either modifying the present IP system or by creating sui generis rights. ${ }^{62}$ Yet, there are also strong arguments against taking this path. In a recent article, Munzer and Raustiala examine existing theories of property ${ }^{63}$ in search of a basis for TK protection and convincingly argue that "provisions aimed at the 'defensive' protection of TK-that is, at halting the (mis) use of TK by nonindigenous actors in patents or copyrighted materials - merit the most support." ${ }^{64}$ They find, however, "much less support for 'offensive' protection, in which TK holders would have the right to control TK that would not otherwise be protected by the existing IP system." ${ }^{\prime 5}$ Some of the concerns Munzer and Raustiala share are that while TK advocates may develop a sound justification for the protection of TK as a form of property, "they must also provide a satisfactory account of why the TK of indigenous peoples, and not other practices and forms of collective or incremental knowledge of other groups, ought to receive legal protection" ${ }^{66}$ and "robust TK protection is in great tension with many core principles of the existing IP system; it is not merely something that can be tacked on as a new right ... [and] TK protection aimed solely at indigenous groups requires a compelling theory of discrimination between indigenous and non-indigenous claims." ${ }^{37}$

It is not the purpose of this article to engage in (or let alone solve) the debate of whether the IP regime or some changes thereof are the best way to respond to the indigenous peoples' worries as far as the protection of their knowledge systems is concerned. Against the backdrop of these discussions and the yet unresolved and very complex issues, ${ }^{68}$ we suggest rather that the digital environment presents opportunities for tailoring the application of existing IP protection mechanisms and for using other, not strictly IP avenues of protecting TCE. ${ }^{69}$ We offer some examples that support this thesis.

\subsubsection{Dynamic Participatory Databases}

As noted earlier, in the digital space, information is organized, searched, and accessed in a new manner. Under these conditions, some technological tools, including digital rights management (DRM) systems, may be applied so as to reflect better the very different and sometimes conflicting demands of indigenous peoples (e.g., for openness and secrecy, or for different levels of access according to privileges or skills of different community members). Such technological tools may enable authorized members to "define and control the rights, accessibility and reuse of their digital resources; uphold traditional laws pertaining to secret/sacred knowledge or objects; prevent the misuse of indigenous heritage in culturally inappropriate or insensitive ways; ensure proper attribution to the traditional owners; and enable indigenous communities to describe their resources in their own words." 70 
Here is a concrete example of utilizing some of these possibilities, and in particular that of tailoring access to and use of knowledge. ${ }^{71}$ Kimberly Christen, an anthropologist, helped recently to create a digital archive containing photos, video, and audio files, all of which are reproductions of cultural artefacts and documents ?4? of the Mukurtu Wumpurrari-kari, an Australian indigenous group. Although the system is open to everyone, it asks everyone who logs in for their name, age, sex, and standing within the community and provides for conditional access according to these data, so that the community's customs regarding what can and cannot be seen, of what is "proper," 72 are reflected. ${ }^{73}$

Christen shares her experience in this context, revealing the opportunities offered by digital technologies:

\begin{abstract}
The flexibility and relative low cost of new technologies have allowed me to work with Warumungu community members in Australia's Northern Territory to create digital projects grounded in their pre-existing, yet always changing, cultural protocols for non-digital cultural materials. These projects-a dynamic online space and a locally adaptable and accessible digital archive-highlight both the processes that anthropologists can engage in and the creative workarounds that exist for extending open access paradigm to include local cultural protocols and practices within the management of cultural and academic knowledge. ${ }^{74}$
\end{abstract}

Similarly, the Indigenous Collections Management Project ${ }^{75}$ has created datasecurity software and metadata standards for the dissemination of culturally sensitive materials, restricting certain types of information that are considered sacred, secret, or of other specific value to the indigenous community. ${ }^{76}$ Overall, such initiatives may contribute to overcoming the fears indigenous peoples have of maltreatment of sacred values and symbols, which are core to their identity and the fears of embracing digital media. They may also facilitate the process of registering and compiling data on TCE that is subsequently easily searchable and manageable for purely anthropological purposes, for communities' own representation and active participation, or for defensive IP protection. ${ }^{77}$

It is essential to distinguish such archives from the conventional ones, where "indigenous voices have had little impact in shaping the information architectures that underlie how cultural heritage is organized and disseminated online." 78 Kansa refers to these old archives as " top down' models of cultural heritage dissemination"79 and notes that "the imposition of a culturally alien database schema dissociates indigenous culture from its context, making it lose much, if not all, of its meaning. Such attempts at cultural heritage documentation may have little relevance to a local community; worse, it may be seen as an act of appropriation, even if motivated by a desire to help." 80

\title{
3.1.2 Tailored Protective Models
}

Next to the modifications that the digital environment has brought about, some of which we have sketched already, the digital space has also substantially increased the economic importance of information, which has correspondingly led 
to a magnified value of copyright law ${ }^{81}$ and to an expansion of its reach. ${ }^{82}$ At the same time, the existing copyright models have been put under pressure. Because they are often too rigid to allow full realization of the possibilities for the production and distribution of digital content (or indeed render them illegal), some new hybrid models of the protection of authors' rights have emerged. One prominent model is the Creative Commons (cc) licence. ${ }^{83}$ It allows management of content under a "some rights reserved" mode, whereby the Creator/Licensor may shape her or his package of rights applying different conditions to the licensed work. These conditions are organized under four categories-attribution, ${ }^{84}$ noncommercial, ${ }^{85}$ no derivative works, ${ }^{86}$ and share alike ${ }^{87}$-and people may distribute their works combining these depending on the purpose intended. ${ }^{88}$ Evidence shows that the availability of such legal constructs feeds positively back to the development of more user-created content and enhances the diversity of content overall. ${ }^{89}$

The cc-licence is also already well spread and embedded in popular content platforms, such as Flickr and Wikipedia, or in the work of public organizations, such as ?5? universities and museums. This large-scale adoption strengthens the network effects and, by practically becoming the standard, gives some legal certainty to the emerging culture of sharing. These softer, less rigid, forms of IP protection may also prove particularly useful for TCE protection and allow the custodians of TCE to shape their presentation reserving some rights of importance to the community ${ }^{90}$ while releasing others and allowing cultural content to be shared, remixed, and reused. Such tailored models may also correspond better to some indigenous forms of creation, where the author as a solitary figure is not central to the creative process. The use of such licenses must not be understood as a purely noncommercial activity: There are options that permit going beyond the cc-licenses (the so-called $\mathrm{CC}+$ ) for not only commercial purposes ${ }^{91}$ but also additional permissions or services, such as warranty, permission to use without attribution, or even access to performance or physical media. ${ }^{92}$

The pursuit of appropriate protection tools for TCE should not remain limited to the cc-licence, which cannot reflect all their specificities, ${ }^{93}$ and attempts should be made to develop new nonstandard licences that fit better the complex indigenous world of sacred, private, secret, and shared. ${ }^{94}$ However, the cc-licences do offer opportunities that must be explored and tested by indigenous communities. ${ }^{95}$ They may also contribute to overcoming the "binary code" in the TCE discussions of either IP or public domain ${ }^{96}$ and allow for "in-between" hybrid solutions. Such opportunities are not to be understood as protection tools stricto sensu but also as promotional ones because they encourage the processes of creation, reformulation, and distribution of indigenous culture.

Finally, another instrument worth exploring as part of the TCE protection toolkit that indigenous communities can resort to in the digital space relates to the use of protocols. As Brian Fitzgerald and Susan Hedge convincingly argue, "the development and implementation of protocols for dealing with cultural materials is becoming an increasingly important means of ensuring that the rights of in- 
digenous peoples are recognized." 97 Protocols are deemed to be "appropriate ways of using Indigenous cultural material, and interacting with Indigenous people and their communities. Protocols encourage ethical conduct and promote interaction based on good faith and mutual respect." 98

But what exactly are protocols, and what role can they play under the conditions of the digital environment? Generally, protocols in the specific context of TCE are meant to function as "ways of actioning" 99 principles of prime importance to indigenous communities. Terri Janke, for the Australia Council for the Arts, has identified nine principles in this context: respect; indigenous control; communication, consultation, and consent; interpretation, integrity, and authenticity; secrecy and confidentiality; attribution; proper returns; continuing cultures; and recognition and protection. ${ }^{100}$ Based on this "framework for respecting Indigenous heritage," ${ }^{101}$ Janke has gone on to elaborate different protocols for different types of media. ${ }^{102}$ "For example, a cultural protocol to action the underlying principle of respect is to acknowledge the Indigenous custodians of country at the site of each performance or installation, or in the introductory on-screen text in a screen-based project." ${ }^{103}$ Some of these protocols are valid or even specifically designed for the Internet.

When online, people commonly use a wide range of services, such as web hosting, search engines, and data storage. The use of these services is based on certain contractual terms that we agree to, most often implicitly (by not opposing to the Terms of Service $[\mathrm{ToS}]$ as announced by the service provider) or through "clickwrap" agreements, where we click on the "I Agree" or similar icon. ${ }^{104}$

In search of ways of implementing protocols in the digital space, Fitzgerald and Hedge have looked at some of the most popular content distribution platforms on the Internet (YouTube, Google, Flickr, and Wikipedia), web-hosting services, and Internet service providers, as well at their ToS. They acknowledge "the significant power that access corporations reserve to themselves under standard user agreements" and find that "while TCE is not explicitly mentioned, words such as (racially) objectionable, offensive, confidential and discriminatory [contained in the ToS] provide some level of discretion." ${ }^{105}$ However, this potential for implementing protocols for the use of TCE on the Internet, which is reinforced by the possibilities of user participation ${ }^{106}$ and by the willingness of corporations to adapt, ${ }^{107}$ coexists with almost complete "ignorance about TCE in the Internet world." ${ }^{08}$

Bearing that in mind, Fitzgerald and Hedge suggest a few paths meant to lead toward "more consideration and protection of TCE in the Internet world." 109 These encompass the following: (1) launching education and awareness campaigns to make access corporations, Internet users, and communities aware of TCE; (2) drafting protocols specifically for the Internet context; (3) adopting ToS expressly mentioning TCE; and (4) notice and take-down procedures. These measures would become active ex ante to prevent the uploading or posting of TCE in inappropriate or offensive ways and ex post to ensure that such material is properly dealt 
with once found or notified. ${ }^{110}$ Overall, protocols could flexibly mediate between the old and the new, and this mediation could be particularly successful in the digital environment, where enhanced user participation and industry-audience communication $^{111}$ make it more receptive to changes.

\subsection{Tools to Promote}

While promotion seems to be the less important member of the pair of "protection and promotion," if we admit that "culture is organic in nature and in order for it to survive, growth and development are necessary," 112 the perspective changes. Creativity and the dynamic aspect of $\mathrm{TCE}^{113}$ come to the fore. This viewpoint transcends the preservation possibilities that digital technologies have enabled and means, above all, protection and promotion of the indigenous communities. For, as Michael F. Brown notes that "if global cultural diversity is preserved on digital recording devices while the people who gave rise to this artistry and knowledge have disappeared, then efforts to preserve intangible property will be judged a failure." 114

In this context, the stress should be on participation. As Eric Kansa accurately notes, "in many ways, a polarized opposition between public domain advocacy and TK protectionism misses the point. Access to and participation in the digital commons (or alternative 'commonses') can be empowering for indigenous communities, just as much as thefts and appropriations of indigenous knowledge and culture can threaten these communities." 115

In view of the salient features of the digital environment sketched in this article, we envisage a few scenarios contributing to the promotion of TCE and to that of indigenous and local communities.

The first scenario unfolds on a commercial level. While "the relationship between tradition, modernity and the market-place is not always perceived to be a happy one"116 (and often isn't ${ }^{117}$ ), "it is important too not to make artificial distinctions between traditional communities and the market-place, as many traditional communities engage in marketing aspects of their culture." 118 The digital environment makes such distinctions even more artificial as it fosters knowledge distribution, regardless of whether it is modern or traditional. ${ }^{119}$

As discussed earlier, digitization has drastically reduced storage and distribution costs and has often had a similar impact on production costs, too (e.g., for digital videos). Although the repercussions of this have been mostly discussed in the context of nonindigenous media, ${ }^{120}$ they are equally applicable to TCE. When digitized, TCE become "present" in the online space, whose capacity to generate markets for niche products offers possibilities for the creation of markets for TCE, both in the form of physical objects and as fixed digitized performances, stories, and songs. This is a unique opening for an incredibly wide variety of TCE forms to reach their audiences. The new demand for TCE could have (at least) a twofold effect. It would mean new (or multiplied) economic opportunities for the indigenous communi- 
ties to market their creations globally and to become actively engaged in global trade. The financial inflow could further lead to substantial strengthening of the welfare of the peoples and their identity. ${ }^{121}$ This empowerment will also feed back positively and foster "creativity, connectivity, and innovation [which] are probably far more effective at preserving and enhancing the dynamism and vitality of traditional knowledge" 122 than protectionism.

The second effect of the digital media affordances is that of promoting the indigenous communities themselves. It is in many ways related to the commercial dimension but could also be singled out as particularly important in its own right:

\begin{abstract}
Providing an online context for local knowledge systems has the potential to help marginalized communities express and reassert identity, autonomy and represent themselves and their knowledge to the broader world community. Communities that have access to vital information and are better able to coordinate action are much more likely to be able to assert themselves and guard against cultural misappropriation. Therefore, development strategies that assist indigenous communities in using and governing their own digital communications resources should compliment TK protection. ${ }^{123}$
\end{abstract}

Indeed, it is even argued that many indigenous communities may overcome isolation through the Internet because it provides "an ideal medium for aboriginal communications" 124 and that it may further prevent the erosion of aboriginal languages, which feeds positively into reaffirmation of cultural traditions and a renewal of traditional relationships with the environment. ${ }^{125}$

Indigenous communities have often found ways on their own to use digital media, in particular as prices of hardware have fallen and a wider range of devices, in particular mobile phones, ${ }^{126}$ have become connected. These efforts must, however, be reinforced in order to enable true participation and involvement of indigenous peoples in the communicative processes of the digital ecosystem. The role of the state as a facilitator in this respect-as a provider of infrastructure and a disseminator of education-could be critical. These efforts would need to be supplemented by civil society initiatives, ${ }^{127}$ broader capacity building, and participatory frameworks ${ }^{128}$ at the national, regional, and global levels with the ultimate goal of allowing indigenous communities to make informed choices about their culture, identity, and development. ${ }^{129}$ On the one hand, in our concrete case, this ?6? would mean informing indigenous communities about the TCE protection toolkit that they can make use of, which comprises a number of IP tools (which are still, despite the limitations of the current IP system, a powerful instrument ${ }^{130}$ ) and taking some non-IP measures. At the same time, raising the awareness among traditional communities of the effects of digital environment and the opportunities it opens would become vital. On the other hand, initiatives aimed at raising the awareness of indigenous culture and peoples in the globalized digital community would also be essential. 


\title{
3.3 Emerging Concerns
}

While the digital environment does create opportunities, there are also a number of emerging concerns. These go beyond the conventional worries that everything can be copied and put on the net. The issues of access and control over information are particularly pertinent and in need of discussion, although they may at first sight appear somewhat distant from the specific debate on TCE protection and promotion.

First, in the narrow context of digital preservation, there are still many unsettled matters. Digital preservation is an essential but also a precarious process:

\begin{abstract}
Embodying creative works in digital form has the unfortunate effect of potentially decreasing their usable lifespan. Digital information is ephemeral: it is easily deleted, written over or corrupted. Because information technology such as hardware, software and digital object formats evolves so rapidly, it can be difficult to access and use digital materials created only a few years ago. Countless born digital works are created every day, but countless born digital works are also lost every day as they are removed, replaced, superseded or left, forgotten, in obsolete formats and media. Digitized and born digital materials are an important part of the world's cultural heritage, but unless active steps are taken to preserve them, they will be lost. ${ }^{131}$
\end{abstract}

In this sense, digital sustainability is certainly very important. "Digital sustainability" means ensuring that digitized formats, especially in the field of cultural heritage, are of high quality and interoperable (both horizontally, i.e., between devices and formats and vertically, i.e., over time). ${ }^{132}$

As the International Study on the Impact of Copyright Law on Digital Preservation ${ }^{133}$ recognizes, copyright law could also be an obstacle to digital preservation projects, because many of the activities involved (such as making multiple copies of a work, distributing copies among multiple institutions, and migrating works to new technological formats and media) demand the exercise of exclusive rights, which in many cases would not fall under the copyright's exceptions and limitations. ${ }^{134}$

In a much broader context, we argue that the sustainability of the digital environment as a whole will become vital. In this sense, developments, which can be characterized as purely technical or "foreign" to the system, may seriously influence the TCE ecology as well. Of particular importance are not only all decisions and developments that influence the interoperability of networks, software, and content ${ }^{135}$ but also questions related to technological and net neutrality. ${ }^{136}$ In these complex matters, it is unlikely that straightforward solutions would be found, but the effort should be directed toward sustaining the generativity of the digital environment, ${ }^{137}$ cautiously balancing private and public interests and avoiding overregulation. ${ }^{138}$

The organization of information by search engines - their precision, positioning, and ultimately control-may also be critical in this context. Vaidhyanathan clearly expresses the fears in this regard related to the role of Google as the ubiq- 
uitous search engine and asks whether public libraries may be more appropriate to administer knowledge. He notes:

\begin{abstract}
It is important to remember that Google serves its own masters: its stockholders and its partners. It does not serve the people of the State of Michigan or the students and faculty of Harvard University. The real risk of privatization is simple: companies fail. Libraries and universities last. Companies wither and crash. Should we entrust our heritage and collective knowledge to a company that has been around for less than a decade? ${ }^{139}$
\end{abstract}

While this scepticism may not be warranted, ${ }^{140}$ this is a telling example of the seismic changes occurring in the information environment and how discrete decisions may radically influence the processes within it. ${ }^{141}$

\title{
4. CONCLUSION
}

The discussions on TCE cannot somehow be placed in a parallel world totally ?7? unlinked from the modern digital networked environment (whose reach will only become greater over time); its underlying issues; and its struggles for innovation, access, and cultural diversity. Taking this broader view of the relationship between digital technologies and TCE, the question is not so much whether indigenous communities use the Internet-a question that would normally lead to a discussion of TCE in a development context and seek instrumentalization of information and communication technologies (ICT). The question is above all how the changed (and changing ${ }^{142}$ ) digital environment influences all the complex institutions and processes of TCE formation, creation, and expression, and whether (and how) one could efficiently provide for the protection and promotion of TCE in this environment.

We hold that the reduced economic thresholds for participation, the new dynamics and diversity of content, and the empowerment of users and communities, as well as some of the purely technical affordances of the digital space, may have brought about a number of opportunities for more meaningful protection and promotion of TCE and of their creators - the multiple indigenous communities scattered throughout the world.

We sketched a few concrete proposals in this regard. Some of them employ digital tools that tailor access to and use of traditional knowledge reflecting the indigenous peoples' demands for distinctions among secret, sacred, and open. We also gave instances of customized protective models, which, without prejudicing the conventional measures for IP protection, make use of innovative (and less burdensome) tools, such as the Creative Commons licensing or different protocols. In terms of TCE promotion, we stressed the importance of sustaining TCE in their dynamic dimension of human creativity, which also necessarily involves sustaining the community. The opportunities opened up in this respect in the digital 
space are multiple. On the one hand, they relate to the facilitation of marketing and trading of TCE forms that is not controlled by intermediaries, which would also be a source of profit for the community. On the other hand, the digital space allows for unprecedented means for participation of indigenous peoples in the processes of culture making, for communicating, reasserting, and renegotiating their traditional values. Certainly, the prospect of a global market for TCE needs to be balanced against the associated risks of commodification and increased misappropriation. Following our analysis, however, the most urgent need appears to be to make indigenous communities aware of the effects of the digital ecosystem, of the possibilities it offers, and of the available protective mechanisms. This would enable them to make informed choices and ultimately fit together on their own the elements that would build an individual and working model for protecting and promoting their TCE, culture, and identity. Fortunately, over the past few years we have observed various initiatives by international, national, and NGOs that go in this direction, departing from the search for one-size-fits-all solutions.

We only looked at a small fraction of the modifications that the digital technologies have triggered in the ways cultural content is created, communicated, and accessed, but it is sufficiently clear that these changes are profound and have multiple repercussions. They accentuate the interrelatedness of effects within the complex system of global and local and make regulatory decisions even more precarious. In this sense, for example, the granting of additional IP protection to forms of TCE cannot be unequivocally assessed as beneficial, because it could have harmful repercussions within the wider system: among other things, reducing creativity and obstructing the production of new cultural content. ${ }^{143}$

The need for safeguarding balances is not limited to the IP regime, although it appears to be the most often named culprit, both in the debates on traditional knowledge protection and those on creativity and digital media. ${ }^{144}$ As Madhavi Sunder aptly puts it:

\begin{abstract}
In the twenty-first century, internal cultural fissures abound. Modern society is becoming increasingly homogeneous across cultures and heterogeneous within them. Globalization, liberalization, the Internet, and Diaspora to name only a few of the forces of modernization-are collapsing cultural barriers and facilitating unprecedented culture flows of people, information, and ideas across traditional cultural boundaries. Increased confrontation with modernity and exposure to alternate ways of life are spurring people within cultures to challenge cultural orthodoxies and demand more equality and autonomy within their cultural contexts. ${ }^{145}$
\end{abstract}

The law has so far remained surprisingly unchanged and "steadfastly committed to the old-world view of cultural diversity as existing across cultures, but not within them" 146 and to protecting distinct rights of cultural groups, such as the right to association, religion, or culture meant to function as a defense against the forces of modernization and change. ${ }^{147}$ We should be cautious that in the process of adapting legal rules for the sake of protecting TCE, these rules are not made 
too rigid, that is, drawing lines in too resolute a way and reestablishing (rather than dismantling) cultural boundaries. ${ }^{148}$ In the meantime, digital technologies as a toolkit can perhaps provide for some hybrid and practical solutions until the larger-scale debates on the underlying and often irreconcilable values are settled.

\section{ENDNOTES}

1. A clear recognition of these "dangers" is paragraph 31 of General Comment No 17 of the UN Committee on Economic, Social and Cultural Rights, which explicitly adds to the obligation to protect author's rights the prevention of "unauthorized use of scientific, literary and artistic productions that are easily accessible or reproducible through modern communication and reproduction technologies." (See UN Committee on Economic, Social and Cultural Rights, "General Comment No 17.")

2. WIPO, Consolidated Analysis of the Legal Protection, para. 4. For examples of appropriation and misappropriation of TCE, see note 1, UN Committee on Economic, Social and Cultural Rights, Annex, para. 94. See also Janke, Minding Culture.

3. Spar, Ruling the Waves.

4. See, for example, the collection of essays in Brownsword, Regulating Technologies.

5. Mueller, "Digital Convergence," 11-28. Gordon Moore of Intel postulated in 1965 that the transistor density on a single integrated circuit microchip would double approximately every 18 months. This rule showing the incredible pace of technological advance is known as Moore's law and (unlikely as it may seem) is still valid.

6. Metcalfe's law holds that the potential value of network increases by the square of the number of nodes, while the fiber law holds that capacity doubles every nine months. See Marsden et al., Assessing Indirect Impacts of the EC Proposals, 72-74. Currently, almost all networks (in developed and even in developing countries) have become IP-based (OECD, Information Technology Outlook 2006).

7. For a precise explanation of how the World Wide Web functions, see Berners-Lee et al., Architecture of the World Wide Web.

8. See, for example, Burri-Nenova, "The Long Tail of the Rainbow Serpent."

9. Weinberger, Everything Is Miscellaneous.

10. We refer here to the so-called "long tail" theory. The name has to do with the image of a demand curve that gets longer and longer and covers more niche nonhit products. The long tail theory was coined by Chris Anderson, chief editor of Wired magazine (Anderson, The Long Tail) but builds on previous and parallel economic research. See in particular Brynjolfsson, Hu, and Smith, "From Niches to Riches"; Brynjolfsson, Hu, and Simester, "Goodbye Pareto Principle, Hello Long Tail." For a critique of Anderson's book, see Wu, "The Wrong Tail."

11. See, for example, the category "Various Artists—International—North America-American Indigenous" as offered on Amazon. The search also connects to similar, either wider or narrower, categories of content (such as "American Indian" or "Tribal Voices").

12. It seems that virtual worlds are currently the only digital spaces that have resisted this trend of localizing content. See Reimsbach-Kounatze and Wunsch-Vincent, "Online Games and Virtual Worlds."

13. See http://meta.wikimedia.org/wiki/List_of_Wikipedias (accessed September 1, 2009).

14. Germann argues that this specificity of cultural goods and services is the main one that commands state intervention for the attainment of cultural objectives (Germann, "Culture in Times of Cholera," 116).

15. The comparison between the offline and online availability of content may be quite striking: A large CD shop may hold about 40,000 titles, while an online music store will have about 30-40 times more. A TV station can broadcast only one particular film in the eight o'clock slot, while its catalogue of digitally stored and distributed films may amount to more than 1,000 titles. Moreover, 
one should note that these are contradistinctions relating to only one particular distribution channel, while in the reality of the digital environment, these are multiple and simultaneously accessible.

16. Also called "wisdom of the crowds." See Surowiecki, The Wisdom of Crowds. See also Shirky, Here Comes Everybody.

17. Brynjolfsson Hu, and Smith, "From Niches to Riches"; Brynjolfsson Hu, and Simester, "Goodbye Pareto Principle."

18. See Naughton, "Our Changing Media Ecosystem."

19. Similarly to the Amazon book-selling platform. See Brynjolfsson, Hu, and Smith, "Consumer Surplus in the Digital Economy."

20. Horlings et al., Contribution to Impact Assessment, 66.

21. On cultural diversity, see Burri-Nenova, "Trade Versus Culture in the Digital Environment."

22. Marsden, Chris, et al. Assessing Indirect Impacts, 22-23.

23. Van Alstyne and Brynjolfsson, "Global Village or Cyber-Balkans?"

24. For data, see Musser, with O'Reilly, "Web 2.0: Principles and Best Practices," 4.

25. Web 2.0 is a phrase coined by O'Reilly Media (http://www.oreilly.com) in 2004. Proponents of the Web 2.0 concept say that it differs from early web development (labeled Web 1.0) in that it moves away from static web sites, the use of search engines, and surfing from one web site to the next, toward a more dynamic and interactive World Wide Web. See O’Reilly, "What Is Web 2.0?" See also OECD, Participative Web: User-Created Content.

26. See, for example, Ku, "The Creative Destruction of Copyright."

27. Benkler, "Freedom in the Commons," 1261. For data on content creation, see OECD, Participative Web, 9-12; Pew, Content Creation Online; Weinberger, Everything Is Miscellaneous.

28. For a critical opinion, see Keen, The Cult of the Amateur.

29. Digitization, both as a tool of expression and as a new cultural communication space "affects the entire spectrum of culture production, distribution and presentation ... [and] brings with it the promise of cultural renewal." See Netherlands Council for Culture, From ICT to E-Culture, 8. See also O’Regan and Goldsmith, "Emerging Global Ecologies of Production.."

30. See WIPO, Traditional Knowledge; WIPO, The Protection of Traditional Cultural Expressions/ Expressions of Folklore: Updated Draft Outline of Policy Options and Legal Mechanisms. See also the WIPO law database available at http://www.wipo.int/tk/en/laws/folklore.html (accessed September 1, 2009).

31. WIPO, The Protection of Traditional Cultural Expressions/Expressions of Folklore: Revised Objectives and Principles, (henceforth the WIPO, Draft TCE Provisions).

32. Article 1(b) of the WIPO, Draft TCE Provisions.

33. Article 1(a) of the WIPO, Draft TCE Provisions.

34. WIPO, The Protection of Traditional Cultural Expressions: Draft Gap Analysis, (henceforth WIPO, TCE Gap Analysis), 3.

35. WIPO, TCE Gap Analysis, 3.

36. WIPO, TCE Gap Analysis, 4.

37. WIPO, TCE Gap Analysis, 4. The WIPO Secretariat clarifies further that "even where an individual has developed a tradition-based creation within his or her customary context, the creation is not 'owned' by the individual but falls within a shared sense of communal responsibility, identity and custodianship. This is what marks such a creation as 'traditional.' TCEs might well have had an author at some stage, but that author is now unknown or simply unlocatable."

38. See Morphy, Aboriginal Art, 67-100.

39. Brown, "Can Culture Be Copyrighted?" See also WIPO, WIPO, Consolidated Analysis of the Legal Protection, para. 9.

40. Daes, Discrimination against Indigenous Peoples, para. 21.

41. Indigenous communities strive also for the achievement of a number of other objectives, such as self-determination or restitution of property. See, for example, Coombe, "The Properties of Culture." See also United Nations Declaration on the Rights of Indigenous Peoples, adopted by the General Assembly September 13, 2007.

42. WIPO, TCE Gap Analysis, 7. 
43. WIPO, TCE Gap Analysis, 7.

44. Munzer and Raustiala, "The Uneasy Case for Intellectual Property Rights," 48.

45. WIPO, TCE Gap Analysis, 8.

46. WIPO, TCE Gap Analysis, 7.

47. UNESCO, Convention on the Protection and Promotion of the Diversity of Cultural Expressions, adopted at the 33rd Session of the General Conference of UNESCO, October 20, 2005, entered into force March 18, 2007. The UN Committee on Economic, Social and Cultural Rights also applies a broader notion of protection. In its General Comment No 17 (see note 1, para. 32), it clarified with specific regard to indigenous peoples that "states parties should adopt measures to ensure the effective protection of the interests of indigenous peoples relating to their productions, which are often expressions of their cultural heritage and traditional knowledge... Such protection might include the adoption of measures to recognize, register and protect the individual or collective authorship of indigenous peoples under national intellectual property rights regimes and should prevent the unauthorized use of scientific, literary and artistic productions of indigenous peoples by third parties."

48. We admit, however, that adopting this looser approach to TCE protection and promotion makes the borderline between the two categories only conditional.

49. See Dutfield, "Promoting Local Innovation," 72-73; see also Anil K. Gupta, "From Sink to Source."

50. Indigenous communities have been "using it to communicate amongst themselves and to others, to gain access to resources, to publish and access databases, and to provide alternative perspectives on issues that are not covered in mainstream media" (Coombe, "Preserving Cultural Diversity," 147).

51. Zellen, "Surf's Up!: NWT's Indigenous Communities", as referred to by Coombe, "Preserving Cultural Diversity," 148. See also Nickerson and Kaufman, "Aboriginal Culture in the Digital Age."

52. Kansa, "Indigenous Heritage and the Digital Commons," 221-222.

53. Helfer, "Regime Shifting: The TRIPs Agreement."

54. Coombe, Schnoor, and Ahmed, "Bearing Cultural Distinction," 916.

55. Bellagio Declaration, March 11, 1993, Bellagio, Italy (reproduced in Boyle, Shamans, Software, and Spleens, 196-200, in Discussion section [footnotes omitted]).

56. "The revoked European patent on a neem oil-based fungicide nicely illustrates these criticisms. First, prior to the 1990s, Indians would have been far less likely to know about foreign patents. The rise of global media and the Internet have changed that. Second, in the past, traditional users of the neem tree would have had little direct incentive to care about foreign patents. But globalization and the rise of international IP protection have again altered the calculus. The prospect that a European patentee might profit by selling neem-based products abroad, coupled with the moral claim that the neem patent was a form of theft, infuriated many Indians. Third, the expansion of patent rights through international agreements has raised the value of TK as an input into patents. The availability of patent protection for an enhanced traditional medicinal cure, for example, raises the value of the TK on which the innovation is based. See Munzer and Raustiala, "The Uneasy Case for Intellectual Property Rights," 51. See also Sunder, "The Invention of Traditional Knowledge," 98.

57. Next to copyright of relevance to TCE protection may also be trademarks and industrial designs protection. On trademarks, see Frankel, "Trademarks, Traditional Knowledge."

58. After yearlong discussions with various stakeholders under the auspices of WIPO's IGC, it appears that specific TCE forms are particularly vulnerable to IP-style exploitation. Among these are "traditional music and songs, visual art (notably painting), traditional musical instruments, handicrafts (including the designs and 'styles' embodied in them), performances of TCEs, sacred and secret TCEs, recordings and documentation of TCEs, and indigenous words, names and symbols." See WIPO, TCE Gap Analysis, 4.

59. Exemplary here is the Lego Bionicles case. See Coombe and Herman, "Rhetorical Values."

60. WIPO, TCE Gap Analysis, 10-11, 19-24. See also WIPO, Consolidated Analysis of the Legal Protection, paras. 102-144.

61. Munzer and Raustiala, “The Uneasy Case for Intellectual Property Rights,” 38. 
62. Munzer and Raustiala, 39. See most notably the work under the auspices of WIPO, Draft TCE Provisions.

63. Including the new and very interesting "stewardship" theory of property developed with respect to the cultural property claims of indigenous peoples by Carpenter, Katyal, and Riley, "In Defense of Property."

64. Munzer and Raustiala, “The Uneasy Case for Intellectual Property Rights," 40.

65. Munzer and Raustiala.

66. Munzer and Raustiala, 41.

67. Munzer and Raustiala, 66.

68. See, for example, Brown, "Heritage Trouble: Recent Work"; and the contributions of von Lewinski (ed.), Indigenous Heritage and Intellectual Property; Antons, Traditional Knowledge; and Graber and Burri-Nenova, Intellectual Property and Traditional Cultural Expressions. For very interesting analysis of TK protection in the broader field of IP reform, see also Sunder, "The Invention of Traditional Knowledge"; Sunder, "IP 3 ."

69. The same approach is also adopted by Fitzgerald and Hedge, "Traditional Cultural Expression and the Internet World."

70. WIPO, Consolidated Analysis of the Legal Protection, Annex, at para. 245, referring among others to Hunter, Koopman, and Sledge, Software Tools for Indigenous Knowledge Management.

71. "Tagging" may be identified as an important Web 2.0 effect. Tagging, which is basically a process of creating labels for online content by attaching a keyword to a piece of information (a picture, article or video) is "a kind of next-stage search phenomenon," whereby online searching is advanced and personalized and digital material is organized in a tailored manner on top of existing formally defined classification schemes. See Pew, Tagging; Weinberger, Everything Is Miscellaneous.

72. See Christen, "Tracking Properness: Repackaging Culture."

73. "Aboriginal Archive Offers New DRM," BBC News.

74. Christen, "Access and Accountability," 4 (references omitted). The two projects mentioned are available at http://www.vectorsjournal.org/issues/03_issue/digitaldynamics and at http://www. mukurtuarchive.org; both accessed September 1, 2009.

75. The Indigenous Collections Management Project is an initiative of the CRC for Enterprise Distributed Systems Technology and the Smithsonian Institute's National Museum of the American Indian Cultural Resources Centre (CRC). The objective of this project is to investigate how information technology tools and standards can be refined and extended to enable indigenous communities to preserve and protect their unique indigenous cultures, knowledge and artefacts while supporting traditional protocols and facilitating better cross-cultural communication and understanding. See http://metadata.net/ICM/ (accessed September 1, 2009).

76. See Kansa, Schultz, and Bissell, "Protecting Traditional Knowledge," 11; Hunter, Koopman, and Sledge, Software Tools for Indigenous Knowledge Management. There are further projects that seek to enable active participation of the community. The Open Context project (http:// opencontext.org/) is a prime example in this category. It was created by the Alexandria Archive Institute and supports a wide range of formally conducted research projects as well as communityled efforts. Its aim is to provide an easy to use tool that "enables communities to organize and share cultural heritage collections in ways that are locally meaningful, but without sacrificing the possibility of interoperability." See Kansa, "Indigenous Heritage and the Digital Commons," 235. See also Kansa and Kansa, "Open Context: Collaborative Data Publication."

77. WIPO keeps track of existing codes, protocols, and policies for developing best practices related to safeguarding of, access to, and control over cultural heritage. See http://www.wipo.int/tk/ en/folklore/culturalheritage/ (accessed September 1, 2009).

78. Kansa, "Indigenous Heritage and the Digital Commons," 223-224. For critique of static databases, see also Brown, "Heritage Trouble: Recent Work"; Brown, Who Owns Native Culture?, $206 \mathrm{ff}$.

79. Kansa, "Indigenous Heritage and the Digital Commons," 223-225.

80. Kansa, "Indigenous Heritage and the Digital Commons," 225 (footnote omitted).

81. Brown, "Heritage Trouble: Recent Work," 44. See also Cohen, "Pervasively Distributed Copyright Enforcement." 
82. Lessig, "(Re)creativity: How Creativity Lives," 19. See also Netanel, "Why Has Copyright Expanded?"

83. See http://creativecommons.org/. There are also some other types of licences designed by the Creative Commons, such as public domain, developing nations, sampling, founder's copyright, GNU, Wiki, and music sharing. The "developing nations" licence, for example, allows a wide range of royaltyfree uses of a work in developing nations, while retaining full copyright in the developed world.

84. You let others copy, distribute, display, and perform your copyrighted work-and derivative works based upon it-but only if they give credit the way you request.

85. You let others copy, distribute, display, and perform your work-and derivative works based upon it-but for noncommercial purposes only.

86. You let others copy, distribute, display, and perform only verbatim copies of your work, not derivative works based upon it.

87. You allow others to distribute derivative works only under a licence identical to the licence that governs your work. For information on all licences, see http://creativecommons.org/about/ licenses/ (accessed September 1, 2009).

88. See, for example, Kelty, "Punt to Culture," 549-554.

89. See OECD, Participative Web: User-Created Content, 14. See also Cobcroft, Building an Australasian Commons: Creative Commons Case Studies.

90. While Kansa et al. find the cc-licence useful for TK/TCE protection, they suggest ways in which it could be moulded to correspond better to the needs of indigenous communities. See Kansa, Schultz, and Bissell, "Protecting Traditional Knowledge." See also Kansa, "Indigenous Heritage and the Digital Commons," 239-243.

91. In practical terms, clicking on the CC+ "permissions beyond" icon would take you to a commercial site, which is not run by Creative Commons, where the terms for the rights beyond those granted by CC licences could be negotiated. There is no limit to the commercial opportunities that might be specified beyond those in the CC licence. The protocol is a general facility to link CC-licensed work with commercial opportunities and to enable hybrid creativity.

92. For more information, see http://wiki.creativecommons.org/Ccplus (accessed September 1, 2009).

93. Kansa, Schultz, and Bissell, "Protecting Traditional Knowledge"; Kansa, "Indigenous Heritage and the Digital Commons." Neither do cc-licences solve all the problems of the existing copyright system: see Niva Elkin-Koren, "What Contracts Cannot Do."

94. Kansa, Finding Common Ground in the Digital Commons.

95. The Creative Commons Case Studies (Cobcroft; see note 89) offer some good examples of cc-licences application in practice. See also Lawrence Lessig, CC as a Global Movement (letter), http:// creativecommons.org/weblog/entry/6155 (November 16, 2006) accessed September 1, 2009.

96. Chander and Sunder, "The Romance of the Public Domain." For a comprehensive analysis, see Waelde and MacQueen, Intellectual Property: The Many Faces of the Public Domain.

97. Fitzgerald and Hedge, Traditional Cultural Expression and the Internet World," 250.

98. Janke, New Media Cultures: Protocols, 2.

99. Janke, New Media Cultures: Protocols, 3.

100. Janke, New Media Cultures: Protocols, 9.

101. Janke, New Media Cultures: Protocols.

102. See these publications of the Australia Council for the Arts: Protocols for Producing Indigenous Australian Media Arts; Protocols for Producing Indigenous Australian Performing Arts; Protocols for Producing Indigenous Australian Music; Protocols for Producing Indigenous Australian Writing; Protocols for Producing Indigenous Australian Visual Arts; all available at http://www.australiacouncil. gov.au/

103. Janke, New Media Cultures: Protocols, 3.

104. There is substantial practice on these types of contracts also called "browse-wrap" and "clickthrough" agreements or licences. See, for example, Moringiello and Reynolds, "Survey of the Law of Cyberspace"; Mootz, "After the Battle of the Forms". For the particular case of virtual worlds and online games, see Burri-Nenova, "User Created Content in Virtual Worlds." 
105. Fitzgerald and Hedge, Traditional Cultural Expression and the Internet World," 260.

106. For the different levels of user participation beyond the mere "read" where users tag, comment, flag, or share content, see Flew, New Media: An Introduction, 31-32.

107. A prime example in this regard is Lego, which agreed to negotiate with the Maori people after having unlawfully used Maori names for its range of toys and computer games called Bionicles. For details, see Fitzgerald and Hedge, Traditional Cultural Expression and the Internet World," 260263, as well as Coombe and Herman, "Rhetorical Values."

108. Fitzgerald and Hedge, Traditional Cultural Expression and the Internet World," 254.

109. Fitzgerald and Hedge, 266.

110. Fitzgerald and Hedge.

111. See Jenkins, Convergence Culture: Where Old and New Media Collide.

112. WIPO, Consolidated Analysis of the Legal Protection, para. 8.

113. Elizabeth Burns Coleman argues that they may indeed be perceived as more dynamic than modern cultural production. See Coleman, "The Disneyland of Cultural Rights to Intellectual Property."

114. Brown, "Heritage Trouble: Recent Work," 54. See also Dutfield, "Protecting and Revitalising Traditional Ecological Knowledge," 109.

115. Kansa, "Indigenous Heritage and the Digital Commons," 221.

116. WIPO, Consolidated Analysis of the Legal Protection, Annex, para. 13.

117. Tyler Cowen is one of the very few who insist that global monopolies and imported technologies have also led to promoting local creativity by generating new markets for innovative, highquality artistic productions. See Cowen, Creative Destruction; Cowen, In Praise of Commercial Culture, in particular $15-43$.

118. WIPO, Consolidated Analysis of the Legal Protection, Annex, at para. 14. "Developing marketable uses for third-world cultural products is 'ultimately perhaps the most effective way to protect their traditions.' Increasingly, third-world artisans recognize that 'except in a museum setting, no traditional craft skill can be sustained unless it has a viable market." Sunder, "The Invention of Traditional Knowledge," 111, citing Liebl and Roy, "Handmade in India: Traditional Craft Skills in a Changing World," 70 and 67, respectively.

119. "Tradition is cultivated, not discovered. The concept of traditional knowledge, too, is a modern invention. Those studying poor people's knowledge warn of the dangers of 'overdrawing the distinction between [traditional knowledge] and modern knowledge." See Sunder, "The Invention of Traditional Knowledge," 110-111, citing Finger, "Introduction and Overview," 31.

120. Benkler, The Wealth of Networks.

121. An excellent example in this regard is the story of the Seminole tribe, which is commercially very active and is now the owner of a number of casinos and the Hard Rock Café chain. See Stumberger, "Der späte Sieg der Seminolen."

122. Kansa, Finding Common Ground in the Digital Commons.

123. Kansa, "Indigenous Heritage and the Digital Commons," 244.

124. Coombe, "Preserving Cultural Diversity," 148.

125. Coombe, "Preserving Cultural Diversity," 147-148, referring to Maffi and Skutnabb-Kangas, "Linguistic Diversity and the 'Curse of Babel." See also Zuckerman, "The Survival of Languages in a Digital Age."

126. See, for example, Sahlfeld, "How Does ICT Work for Development."

127. Brown, "Heritage as Property," 60.

128. Kansa, "Indigenous Heritage and the Digital Commons," 226-230. See also Dutfield, "Promoting Local Innovation," 75.

129. Sunder, in "The Invention of Traditional Knowledge" and "IP3", argues along the same lines borrowing from the influential theory of Amartya Sen of "development as freedom." See Sen, Development as Freedom.

130. Coombe, Schnoor, and Ahmed, "Bearing Cultural Distinction." Some governments have taken steps toward informing and educating the indigenous and local communities within their State territories. See New Zealand Ministry of Economic Development, Te Mana Taumara Mātauranga, and the diverse protocols issued by the Australia Council for the Arts in note 102. 
131. International Study on the Impact of Copyright Law on Digital Preservation, 1.

132. Netherlands Council for Culture, From ICT to E-Culture. See also Kansa, "Indigenous Heritage and the Digital Commons," 234.

133. Netherlands Council for Culture, From ICT to E-Culture. See also Kansa, "Indigenous Heritage and the Digital Commons." The study looks at both the ongoing major digital preservation projects in a number of selected countries (Australia, the Netherlands, United Kingdom, and the United States) and at the state of copyright law there, and makes some suggestions for improvements.

134. International Study on the Impact of Copyright Law on Digital Preservation, Netherlands Council for Culture, From ICT to E-Culture, 2. See also Pessach, "Digitization and Copyright Law."

135. On interoperability, see Gasser and Palfrey, Breaking Down Digital Barriers.

136. The principle of net(work) neutrality or in its broader sense, the end-to-end principle, essentially holds that the network should be neutral to the content being passed and that intermediaries should pass all packets, while the intelligence is located at the edges of the network. See, for example, Wu, "Network Neutrality, Broadband Discrimination"; Crawford, "Network Rules."

137. Zittrain, "The Generative Internet."

138. Digital technologies have also been employed for less benevolent purposes, such as Internet filtering. See Deibert et al., Access Denied.

139. Vaidhyanathan, "The Googlization of Everything," 1220. See also Bracha and Pasquale, "Federal Search Commission?”

140. For a more optimistic vision of Google's role, see Kurtz, "Copyright and the Human Condition," 1250-1251.

141. See a very interesting article in this regard, Guy Pessach, "[Networked] Memory Institutions."

142. Forecasts predict, for example, that by 2020 a global, low-cost network will be available to most people worldwide. See Pew, The Future of the Internet II.

143. Gasser and Ernst, From Shakespeare to DJ Danger Mouse. See also Coombe, "Protecting Cultural Industries," 613.

144. See, for example, Lessig, Free Culture: How Big Media Uses Technology.

145. Sunder, "Cultural Dissent," 497-498 (emphases in the original; footnotes omitted).

146. Sunder, "Cultural Dissent," 500.

147. Sunder, "Cultural Dissent."

148. Sunder, "Cultural Dissent," 566-567.

\section{BIBLIOGRAPHY}

“Aboriginal Archive Offers New DRM," BBC News. October 22, 2008.

Anderson, Chris. The Long Tail: Why the Future of Business Is Selling Less of More. New York: Hyperion, 2006.

Anil K. Gupta. "From Sink to Source: The Honey Bee Network Documents Indigenous Knowledge and Innovations in India." Innovations: Technology, Governance, Globalization 1, no. 3 (2006): 49-66.

Antons, Christoph, ed. Traditional Knowledge, Traditional Cultural Expressions and Intellectual Property Law in the Asia-Pacific Region, Alphen aan den Rijn, Netherlands: Kluwer Law International, 2009.

Benkler, Yochai. "Freedom in the Commons: Towards a Political Economy of Information." Duke Law Review 52 (2003): 1245-1276.

The Wealth of Networks: How Social Production Transforms Markets and Freedom. New Haven, CT: Yale University Press, 2006. 
Berners-Lee, Tim, et al. Architecture of the World Wide Web, Vol. 1, W3C Recommendation. 〈www.w3.org/TR/webarch/〉 (December 15, 2004) accessed September 1, 2009.

Boyle, James. Shamans, Software, and Spleens: Law and the Construction of the Information Society. Cambridge, MA: Harvard University Press, 1996.

Bracha, Oren, and Frank Pasquale. "Federal Search Commission? Access, Fairness, and Accountability in the Law of Search." Cornell Law Review 93 (2008): 1149-1209.

Brown, Michael F. “Can Culture Be Copyrighted?” Current Anthropology 39, no. 2 (1998): 193-206.

Who Owns Native Culture? Cambridge, MA: Harvard University Press, 2003.

"Heritage as Property." In Property in Question: Value Transformation in the Global Economy, edited by Katherine Verdery and Caroline Humphrey, 49-68. Oxford, UK: Berg, 2004.

. "Heritage Trouble: Recent Work on the Protection of Intangible Cultural Property." International Journal of Cultural Property 12 (2005): 40-61.

Brownsword, Roger, ed. Regulating Technologies: Legal Futures, Regulatory Frames and Technological Fixes. Oxford: Hart, 2008.

Brynjolfsson, Erik, Yu Hu, and Duncan Simester, "Goodbye Pareto Principle, Hello Long Tail: The Effect of Search Costs on the Concentration of Product Sales." Cambridge, MA: MIT Center for ?13? Digital Business Research Paper, 2007.

, Yu Hu, and Michael D. Smith. "Consumer Surplus in the Digital Economy: Estimating the Value of Increased Product Variety at Online Booksellers." MIT Sloan Working Paper No 4305, Cambridge, MA, 2003.

, Yu Hu, and Michael D. Smith. "From Niches to Riches: The Anatomy of the Long Tail." Sloan Management Review 47, no. 4 (2006): 67-71.

Burri-Nenova, Mira. "The Long Tail of the Rainbow Serpent: New Technologies and the Protection and Promotion of Traditional Cultural Expressions." In Intellectual Property and Traditional Cultural Expressions in a Digital Environment, edited by Christoph Beat Graber and Mira Burri-Nenova, 205236. Cheltenham, UK: Edward Elgar, 2008.

."Trade Versus Culture in the Digital Environment: An Old Conflict in Need of a New Definition." Journal of International Economic Law 12, no. 1 (2009): 17-62.

"User Created Content in Virtual Worlds and Cultural Diversity." In Governance of Digital Game Environments and Cultural Diversity, edited by Christoph Beat Graber and Mira BurriNenova. Cheltenham, UK: Edward Elgar, 2009 (forthcoming; on file with the author).

Carpenter, Kristen A., Sonia K. Katyal, and Angela R. Riley. "In Defense of Property." Yale Law Journal 118 (2009): 1022-1125.

Chander, Anupam, and Madhavi Sunder. "The Romance of the Public Domain." California Law Review 92 (2004): 1331-1373.

Christen, Kimberly. “Tracking Properness: Repackaging Culture in a Remote Australian Town.” Cultural Anthropology 21, no. 3 (2006): 416-446.

"Access and Accountability: The Ecology of Information Sharing in the Digital Age." Anthropology News (April 2009): 4-5. 
Cobcroft, Rachel, ed. Building an Australasian Commons: Creative Commons Case Studies, Vol. 1, Creative Commons Clinic. Australian Research Council, Centre of Excellence for Creative Industries and Innovation, 2008. Also available at $\langle\mathrm{http}: / /$ creativecommons.org.au/casestudiesvol1〉 (2008) accessed September 1, 2009.

Cohen, Julie E. “Pervasively Distributed Copyright Enforcement.” Georgetown Law Journal 95 (2006): $1-48$.

Coleman, Elizabeth Burns. "The Disneyland of Cultural Rights to Intellectual Property: Anthropological and Philosophical Perspectives." In Intellectual Property and Traditional Cultural Expressions in a Digital Environment, edited by Christoph Beat Graber and Mira Burri-Nenova. Cheltenham, UK: Edward Elgar, 2008.

Coombe, Rosemary J. "The Properties of Culture and the Possession of Identity: Postcolonial Struggle and the Legal Imagination." In Borrowed Power: Essays on Cultural Appropriation, edited by Bruce Ziff and Pratima V. Rai, 74-96. New Brunswick, NJ: Rutgers University Press, 1997.

"Preserving Cultural Diversity Through the Preservation of Biological Diversity: Indigenous Peoples, Local Communities, and the Role of Digital Technologies." In The Gender of Genetic Futures, edited by Fiona Miller et al., 132-160. NNEWH Working Paper Series, 2000.

"Protecting Cultural Industries to Promote Cultural Diversity: Dilemma for International Policy-Making Posed by the Recognition of Traditional Knowledge." In International Public Goods and Transfer of Technology Under a Globalized Property Regime, edited by Keith E. Maskus and Jerome H. Reichman, 559-614. Cambridge, UK: Cambridge University Press, 2005.

— and Andrew Herman. "Rhetorical Values: Property, Speech, and the Commons on the World Wide Web” Anthropological Quarterly 77, no. 3 (2004): 559-574.

, Steven Schnoor, and Mohsen Ahmed. "Bearing Cultural Distinction: Informational Capitalism and New Expectations for Intellectual Property." UC Davis Law Review 40 (2007): 891-917.

Cowen, Tyler. In Praise of Commercial Culture. Cambridge, MA: Harvard University Press, 1998.

Creative Destruction: How Globalization Is Changing the World's Cultures. Princeton, NJ: Princeton University Press, 2002.

Crawford, Susan P. “Network Rules.” Law and Contemporary Problems 70, no. 2 (2007): 51-90.

Daes, Erica-Irene. Discrimination against Indigenous Peoples: Study on the Protection of the Cultural and Intellectual Property of Indigenous Peoples (E/CN.4/Sub.2/1993/28). New York: United Nations Economic and Social Council, Commission on Human Rights, 1993.

Deibert, Ronald J., John G. Palfrey, Rafal Rohozinski, and Jonathan Zittrain. Access Denied: The Practice and Policy of Global Internet Filtering. Cambridge, MA: MIT Press, 2007.

Dutfield, Graham. "Protecting and Revitalising Traditional Ecological Knowledge: Intellectual Property Rights and Community Knowledge Databases in India." In Intellectual Property Aspects of Ethnobiology, Perspectives on Intellectual Property, Vol. 6, edited by Michael Blakeney, 103-122. London: Sweet and Maxwell, 1999.

"Promoting Local Innovation as a Development Strategy." Innovations: Technology, Governance, Globalization 1, no. 3 (2006): 67-77.

Elkin-Koren, Niva. "What Contracts Cannot Do: The Limits of Private Ordering in Facilitating a Creative Commons." Fordham Law Review 74, no. 2 (2005): 375-422. 
Finger, J. Michael. “Introduction and Overview.” In Poor People's Knowledge: Promoting Intellectual Property in Developing Countries, edited by J. Michael Finger and Philip Schuler, 1-36. Oxford, UK: Oxford University Press; Washington, DC: World Bank Publications.

Fitzgerald, Brian F., and Susan Hedge. "Traditional Cultural Expression and the Internet World." In Traditional Knowledge, Traditional Cultural Expressions and Intellectual Property Law in the AsiaPacific Region, edited by Christoph Antons, 245-272. Alphen aan den Rijn, Netherlands: Kluwer Law International, 2009.

Flew, Terry. New Media: An Introduction, 3rd ed. Oxford, UK: Oxford University Press, 2008.

Frankel, Susy. “Trademarks, Traditional Knowledge and Cultural Intellectual Property Rights.” In Trademark Law and Theory: A Handbook of Contemporary Research, edited Graeme B. Dinwoodie and Mark D. Janis, 433-463. Cheltenham, UK: Edward Elgar, 2007.

Gasser, Urs, and Silke Ernst, From Shakespeare to DJ Danger Mouse: A Quick Look at Copyright and User Creativity in the Digital Age. Berkman Center for Internet and Society Research Publication No. 05, 2006.

, and John Palfrey, Breaking Down Digital Barriers. Berkman Publication Series. 〈http:// cyber.law.harvard.edu/interop/> (November 2007) accessed September 1, 2009.

Germann, Christophe. "Culture in Times of Cholera: A Vision for a New Legal Framework Promoting Cultural Diversity” ERA—Forum 6, no. 1 (2005): 109-130.

Graber, Christoph Beat, and Mira Burri-Nenova, eds. Intellectual Property and Traditional Cultural Expressions in a Digital Environment, Cheltenham, UK: Edward Elgar, 2008.

Helfer, Laurence R. "Regime Shifting: The TRIPs Agreement and New Dynamics of International Intellectual Property Lawmaking." Yale Journal of International Law 29, no. 1 (2004): 1-83.

Horlings, Edwin, et al. Contribution to Impact Assessment of the Revision of the Television Without Frontiers Directive. Cambridge, UK: RAND Europe, 2005.

Hunter, Jane, Bevan Koopman, and Jane Sledge. Software Tools for Indigenous Knowledge Management. 〈www.archimuse.com/mw2003/papers/hunter/hunter.html〉 (September 2002) accessed September 1, 2009.

International Study on the Impact of Copyright Law on Digital Preservation. A Joint Report of the Library of Congress National Digital Information Infrastructure and Preservation Program, the Joint Information Systems Committee, the Open Access to Knowledge (OAK) Law Project and the SURFfoundation. Brisbane, Australia: Queensland University of Technology, 2008.

Janke, Terri. New Media Cultures: Protocols for Producing Indigenous Australian New Media. Report prepared for the Aboriginal and Torres Strait Islander Board of the Australia Council for the Arts. Sydney: Australia Council for the Arts, 2002.

Minding Culture: Case Studies on Intellectual Property and Traditional Cultural Expressions. Geneva: WIPO, 2003.

Jenkins, Henry. Convergence Culture: Where Old and New Media Collide. Cambridge, MA: MIT Press, 2006.

Kansa, Eric. Finding Common Ground in the Digital Commons. 〈http://icommons.org/articles/findingcommon-ground-in-the-digital-commons (August 14, 2007) last accessed September 1, 2009. 
. "Indigenous Heritage and the Digital Commons." In Traditional Knowledge, Traditional Cultural Expressions and Intellectual Property Law in the Asia-Pacific Region, edited by Christoph Antons, 219-244. Alphen aan den Rijn, Netherlands: Kluwer Law International, 2009.

, and Sarah Whitcher Kansa. "Open Context: Collaborative Data Publication to Bridge Field Research and Museum Collections.” In International Cultural Heritage Informatics Meeting (ICHIM07) Proceedings, edited by Jennifer Trant and David Bearman. Toronto, Canada: Archives and Museum Informatics, 2007.

Kansa, Eric C., Jason Schultz, and Ahrash N. Bissell. "Protecting Traditional Knowledge and Expanding Access to Scientific Data: Juxtaposing Intellectual Property Agendas via a 'Some Rights Reserved' Model." International Journal of Cultural Property 12 (2005): 285-314.

Keen, Andrew. The Cult of the Amateur: How Today's Internet Is Killing Our Culture. New York: Doubleday, 2007.

Kelty, Christopher M. "Punt to Culture." Anthropological Quarterly 77, no. 3 (2004): 547-558.

$\mathrm{Ku}$, Raymond Shih Ray. "The Creative Destruction of Copyright: Napster and the New Economics of Digital Technology." University of Chicago Law Review 69, no. 1 (2002): 263-324.

Kurtz, Leslie A. “Copyright and the Human Condition.” UC Davis Law Review 40 (2007): 1233-1252.

Lessig, Lawrence. Free Culture: How Big Media Uses Technology and the Law to Lock Down Culture and Control Creativity. New York: Penguin, 2004.

. "(Re)creativity: How Creativity Lives." In Copyright and Other Fairy Tales: Hans Christian and the Commodification of Creativity, edited by Helle Porsdam, 15-22. Cheltenham, UK: Edward Elgar, 2006.

Liebl, Maureen, and Tirthanker Roy. "Handmade in India: Traditional Craft Skills in a Changing World." In Poor People's Knowledge: Promoting Intellectual Property in Developing Countries, edited by J. Michael Finger and Philip Schuler, 53-74. Oxford, UK: Oxford University Press, and Washington, DC: World Bank Publications.

Maffi, L., and T. Skutnabb-Kangas. "Linguistic Diversity and the 'Curse of Babel.” In Cultural and Spiritual Values of Biodiversity (United Nations Environment Programme). London: Intermediate Technology Publications, 2000.

Marsden, Chris, et al. Assessing Indirect Impacts of the EC Proposals for Video Regulation, Cambridge, UK: RAND Europe, 2006.

Mootz III, Francis J. "After the Battle of the Forms: Commercial Contracting in the Electronic Age." I/S A Journal of Law and Policy for the Information Society 4, no. 2 (2008): 271-343.

Moringiello, Juliet M., and William L. Reynolds. "Survey of the Law of Cyberspace: Electronic Contracting Cases 2007-2008." Business Lawyer 64, no. 1 (2008): 199-219.

Morphy, Howard. Aboriginal Art. London: Phaidon, 1998.

Mueller, Milton L. "Digital Convergence and Its Consequences." Javnost—The Public 6, no. 3 (1999): $11-28$.

Munzer, Stephen R., and Kal Raustiala. “The Uneasy Case for Intellectual Property Rights in Traditional Knowledge." Cardozo Arts and Entertainment Law Journal 27 (2009): 37-97.

Musser, John, with Tim O’Reilly. “Web 2.0: Principles and Best Practices.” O’Reilly Radar, 2006. 
Naughton, John. “Our Changing Media Ecosystem.” In Communications: The Next Decade, edited by Ed Richards et al., 41-50. London: Ofcom, 2006.

Netanel, Neil W. "Why Has Copyright Expanded? Analysis and Critique." In New Directions in Copyright Law, Vol. 6, edited by Fiona Macmillan, 3-34. Cheltenham, UK: Edward Elgar, 2008.

Netherlands Council for Culture. From ICT to E-Culture: Advisory Report on the Digitalisation of Culture and the Implications for Cultural Policy. Submitted to the State Secretary for Education, Culture and Science, 2004.

New Zealand Ministry of Economic Development. Te Mana Taumara Mātauranga: Intellectual Property Guide for Māori Organizations and Communities. Wellington, NZ: New Zealand Ministry of Economic Development, 2007.

Nickerson, Marcia, and Jay Kaufman. "Aboriginal Culture in the Digital Age." Policy, Politics and Governance 10 (2005): $1-7$.

OECD. Information Technology Outlook 2006. Paris: OECD, 2007. . Participative Web: User-Created Content. DSTI/ICCP/IE(2006)7/FINAL, 12 April 2007.

O’Regan, Tom, and Ben Goldsmith. "Emerging Global Ecologies of Production." In The New Media Book, edited by Dan Harries, 92-105. London: British Film Institute.

O’Reilly, Tim. "What Is Web 2.0? Design Patterns and Business Models for the Next Generation Software." Communications and Strategies 65 (2007): 17-37.

Pessach, Guy. "Digitization and Copyright Law: Taking Stock and Looking Ahead." Journal of International Media and Entertainment Law 1, no. 2 (2007): 253-282.

." [Networked] Memory Institutions: Social Remembering, Privatization and its Discontents." Cardozo Arts and Entertainment Law Journal 26, no. 1 (2008): 71-149.

Pew Internet \& American Life Project. Content Creation Online. February 29, 2004.

Protocols for Producing Indigenous Australian Media Arts, 2nd ed. Sydney: Australia Council for the Arts. 〈www.australiacouncil.gov.au/〉 (2007) accessed September 1, 2009.

Protocols for Producing Indigenous Australian Music, 2nd ed. Sydney: Australia Council for the Arts. 〈www.australiacouncil.gov.au/〉 (2007) accessed September 1, 2009.

Protocols for Producing Indigenous Australian Performing Arts, 2nd ed. Sydney: Australia Council for the Arts. 〈www.australiacouncil.gov.au/〉 (2007) accessed September 1, 2009.

Protocols for Producing Indigenous Australian Visual Arts, 2nd ed. Sydney: Australia Council for the Arts. 〈www.australiacouncil.gov.au/〉 (2007) accessed September 1, 2009.

Protocols for Producing Indigenous Australian Writing, 2nd ed. Sydney: Australia Council for the Arts. 〈www.australiacouncil.gov.au/〉 (2007) accessed September 1, 2009.

Reimsbach-Kounatze, Christian, and Sacha Wunsch-Vincent. "Online Games and Virtual Worlds: Business and Policy Developments." In Governance of Digital Game Environments and Cultural Diversity, edited by Christoph Beat Graber and Mira Burri-Nenova. Cheltenham, UK: Edward Elgar, ?32? 2009 (forthcoming; on file with the author). 
Sahlfeld, Miriam. "How Does ICT Work for Development: A Review of the Challenges and Opportunities." African Technology Development Forum 4, no. 1 (2007): 22-36.

Sen, Amartya. Development as Freedom. Oxford, UK: Oxford University Press, 1999.

Shirky, Clay. Here Comes Everybody: The Power of Organizing Without Organizations. London: Penguin, 2008.

Spar, Debora L. Ruling the Waves: From the Compass to the Internet, a History of Business and Politics Along the Technological Frontier. Orlando, FL: Harcourt, 2001.

Stumberger, Rudolf. “Der späte Sieg der Seminolen.” Neue Zürcher Zeitung 20, (August 2007).

Sunder, Madhavi. “Cultural Dissent.” Stanford Law Review 54 (2001): 495-567.

"IP3." Stanford Law Review 59, no. 2 (2006): 257-332.

_. "The Invention of Traditional Knowledge." Law and Contemporary Problems 70, no. 2 (2007): 97-124.

Surowiecki, James. The Wisdom of Crowds: Why the Many Are Smarter Than the Few and How Collective Wisdom Shapes Business, Economies, and Nations. New York: Anchor, 2003.

UN Committee on Economic, Social and Cultural Rights. "General Comment No 17: The Right of Everyone to Benefit from the Protection of the Moral and Material Interests Resulting from Any Scientific, Literary or Artistic Production of Which He Is the Author." (Article 15(1)(c)), UN Doc. E/C.12/2005, November 21, 2005.

Vaidhyanathan, Siva. "The Googlization of Everything and the Future of Copyright." UC Davis Law Review 40 (2007): 1207-1231.

Van Alstyne, Marshall, and Erik Brynjolfsson. "Global Village or Cyber-Balkans? Modeling and Measuring the Integration of Electronic Communities." Management Science 51, no. 6 (2005): 851-868.

von Lewinski, Silke, ed. Indigenous Heritage and Intellectual Property: Genetic Resources, Traditional Knowledge and Folklore, 2nd ed. The Hague, Netherlands: Kluwer Law International, 2008.

Waelde, Charlotte, and Hector MacQueen, eds. Intellectual Property: The Many Faces of the Public Domain. Cheltenham, UK: Edward Elgar, 2007.

Weinberger, David. Everything Is Miscellaneous: The Power of the New Digital Disorder. New York: Henry Holt, 2007.

WIPO. Traditional Knowledge: Operational Terms and Definitions. WIPO/GRTKF/IC/3/9. May 20, 2002.

Consolidated Analysis of the Legal Protection of Traditional Cultural Expressions. WIPO/ GRTKF/IC/5/3, Annex. May 2, 2003.

The Protection of Traditional Cultural Expressions/Expressions of Folklore: Revised Objectives and Principles. (Unaltered in the subsequent WIPO documents WIPO/GRTKF/IC/9/4, January 9, 2006; WIPO/GRTKF/IC/10/4, October 2, 2006; WIPO/GRTKF/IC/11/4(a), April 26, 2007, and WIPO/ GRTKF/IC/11/4(c), December 6, 2007), Annex, at Article 1. April 8, 2005.

The Protection of Traditional Cultural Expressions/Expressions of Folklore: Updated Draft Outline of Policy Options and Legal Mechanisms. WIPO/GRTKF/IC/9/INF/4. March 27, 2006. 
The Protection of Traditional Cultural Expressions: Draft Gap Analysis. WIPO/GRTKF/IC/ 13/4 (b) Rev., Annex 1. October 11, 2008.

Wu, Tim. "Network Neutrality, Broadband Discrimination." Journal on Telecommunications and High Technology Law 2 (2003): 141-175.

_. "The Wrong Tail: How to Turn a Powerful Idea into a Dubious Theory of Everything." Slate, July 21, 2006.

Zellen, Barry. "Surf's Up! NWT's Indigenous Communities Await a Tidal Wave of Electronic Information." Cultural Survival Quarterly 21, no. 4 (1998): 148.

Zittrain, Jonathan L. “The Generative Internet.” Harvard Law Review 119, no. 7 (2006): 1974-2040.

Zuckerman, Ethan. "The Survival of Languages in a Digital Age." My Heart's in Accra (blog). ?36? $\langle$ www.ethanzuckerman.com/blog/?p=1426〉 (May 16, 2007) accessed September 1, 2009. 